\title{
The haematology of hyperthyroidism: abnormalities of erythrocytes, leucocytes, thrombocytes and haemostasis
}

\author{
H.C. Ford and J.M. Carter \\ Department of Pathology, Wellington School of Medicine, Wellington Hospital, P.O. Box 7343, \\ Wellington, New Zealand
}

\begin{abstract}
Summary: The abnormalities of erythrocytes, leucocytes, thrombocytes and coagulation that have been reported, particularly in more recent years, to be associated with hyperthyroidism are surveyed. Several areas are highlighted where further investigations could lead to clinically useful insights, improved information about the haematological processes involved or to a better understanding of thyroid hormone action.
\end{abstract}

\section{Introduction}

Although clinically important haematological abnormalities are unusual in patients with hyperthyroidism, the haematological system is, nonetheless, greatly affected by the thyrotoxic state. Hyperthyroidism can have different causes, the more common of which are autoimmunity (Graves' disease), toxic adenomas (multinodular goitre or single nodule), or the administration of thyroid hormone (used to induce experimental hyperthyroidism). Graves' disease is responsible for most cases of clinical hyperthyroidism, particularly in younger patients. Some of the haematological abnormalities that occur may depend on the cause of the hyperthyroidism. For example, in Graves' disease certain haematological changes may have an immunological basis rather than being caused by thyroid hormone excess per se.

Because understanding of the mechanisms of action of thyroid hormones is incomplete, most of the haematological changes that have been reported cannot be adequately explained. Recent advances in our understanding of thyroid hormone action at the cellular level have been recently reviewed. ${ }^{1}$ In hormone-responsive tissues, nuclear receptors for tri-iodothyronine $\left(\mathrm{T}_{3}\right)$ are present and are involved in the initiation of hormone action. The receptors have been identified as non-histone proteins of molecular weight about 50,000. Recent work has suggested that the receptor is closely related to the

Correspondence: H.C. Ford, M.D., Ph.D.

Accepted: 11 May 1988 product of the cellular proto-oncogene c-erb-A and thus is a member of the family of receptors that includes those for steroid hormones, vitamin D and retinoic acid. After binding to the receptor, it is postulated that the $T_{3}$-receptor complex binds to specific regions of the DNA and alters gene expression. Whether or not thyroid hormones can initiate cellular responses through direct interaction with extranuclear components, such as mitochondria or receptors on the plasma membrane, remains an open question. It is likely that careful study of certain of the haematological abnormalities in hyperthyroidism would lead to major advancements in our understanding of the mechanisms of action of thyroid hormones. The stimulatory effect of thyroid hormones on glucose metabolism in the erythrocyte, a cell without mitochondria or a nucleus, is an example. On a more clinical level, there is a need for a simple, reliable assay of the effects of thyroid hormones at the tissue level. The measurement of the basal metabolic rate has proved unwieldy, unreliable and imprecise in many instances. Currently, the physician relies largely on indirect measures such as hormone levels in blood and clinical evaluation to ascertain the thyroid hormone status of patients. Although these measures are often sufficient, haematological abnormalities offer the potential of making a major contribution in this area.

This review attempts to survey many of the abnormalities of erythrocytes, leucocytes, thrombocytes and coagulation that have been reported,

(C) The Fellowship of Postgraduate Medicine, 1988 
particularly in more recent years, to be associated with hyperthyroidism and to highlight the areas where further investigations are needed to increase our understanding of the mechanisms involved. In most instances, we have not compared the haematological change seen in hyperthyroidism with the change, or lack thereof, that has been reported in hypothyroidism. To do so regularly would have extended the review unduly. The well-known association of pernicious anaemia with Graves' disease has been extensively reviewed ${ }^{2,3}$ and will not be further discussed in this review.

\section{Erythrocytes}

\section{Kinetics and indices (Table I)}

The earlier studies on erythrocyte kinetics in hyperthyroidism have been comprehensively reviewed. ${ }^{2,3}$ The total red blood cell mass is increased ${ }^{4-6}$ even though the survival time of erythrocytes is shortened, at least in some patients. ${ }^{5,7.8}$ Total red cell mass is directly related to lean body mass and the suggested basis for this correlation is that oxygen-carrying power (the red cell mass) is regulated by the basal oxygen requirements of the actively-metabolizing lean body mass; ${ }^{4}$ the oxygen requirement of adipose tissue being relatively low. Total blood volume is also related to the oxygen requirement as expressed by the basal metabolic rate, and is elevated in hyperthyroidism. ${ }^{9}$ The observation that indices such as haematocrit, haemoglobin and red cell count are not elevated in hyperthyroidism despite an increase in total red cell mass has been attributed to this concomitant increase in plasma volume. ${ }^{5.9}$ Frank polycythaemia, however, may be seen on rare occasions. ${ }^{6}$

The mechanism whereby thyroid hormones increase erythropoiesis is not entirely clear. There is evidence that erythropoietin levels are increased, probably in response to increased cellular oxygen need. ${ }^{4,5,10}$ In vitro culture studies suggest that thyroid hormones directly stimulate erythroid progenitor cells and that this effect may be mediated via $\beta_{2}$-adrenergic receptors. ${ }^{11,12}$ Recently evidence has been presented suggesting that the stimulating

Table I Abnormalities of erythrocyte kinetics and indices in hyperthyroidism

Total mass increased ${ }^{4-6}$

Erythropoiesis increased 5

Iron turnover increased ${ }^{5,6,17}$

Mean corpuscular haemoglobin decreased ${ }^{18-21}$

Mean corpuscular volume decreased ${ }^{18-21}$

Haemoglobin decreased ${ }^{18-20}$

Haematocrit decreased ${ }^{18-20}$ effects of thyroid hormones on erythropoiesis is not direct, but is mediated via mononuclear cells which release tissue-specific erythroid-stimulating factor(s) on exposure to thyroid hormones. ${ }^{13}$

The increase in erythropoiesis in hyperthyroidism is reflected in the bone marrow which undergoes erythyroid hyperplasia. ${ }^{5,14,15}$ Ferrokinetic data confirm that haemoglobin synthesis is increased; in the thyrotoxic patient the plasma iron clearance time is shortened and the plasma iron turnover and red blood cell radioiron incorporation increased $5,16,17$ In some patients, however, there is evidence of ineffective erythropoiesis. Lahtinen ${ }^{18}$ examined the bone marrow of 19 thyrotoxic patients both before therapy and after euthyroidism had been attained. The proportion of sideroblasts and the amount of haemosiderin were significantly higher when the patients were hyperthyroid and the marrow contained pathological sideroblasts with coarse, perinuclear iron granules. Further evidence that ineffective erythropoiesis may occur is that some thyrotoxic patients show reduced iron utilization ${ }^{17}$ and a reduced mean corpuscular volume is frequently observed. ${ }^{18-21}$ It has been suggested that these manifestations of ineffective erythropoiesis are most likely to be found in those patients with very severe or long-standing thyrotoxicosis. ${ }^{17}$

The reduced mean corpuscular volume observed in hyperthyroidism contrasts with the macrocytosise of hypothyroidism and points to a role for thyroid? hormone in determining erythrocyte size.

As a result of the above described variations in erythropoiesis and the changes in plasma volume which occur in the hyperthyroid patient, it is not surprising that the haemoglobin level may be high, low or normal. In the majority of patients, however, the routine full blood count is essentially normal with minimal changes in the haemoglobin level, red cell count, mean corpuscular volume, reticulocyte count ${ }^{14}$ or blood viscosity. ${ }^{22}$ If, as is often the case, there is also a deficiency of iron, vitamin $B_{12}$ or folate, the characteristic features of these deficiencies will be seen. Iron deficiency, in particular, is commonly seen since the majority of hyperthyroid patients are menstruating females. Since hyperthyroidism may interfere with the ability of the marrow to utilise iron, a poor response to iron therapy may be seen. ${ }^{17}$

\section{Biochemistry (Table II)}

Most, ${ }^{23-29}$ but not all, ${ }^{30}$ investigators have found the activity of the $\mathrm{Na}^{+}, \mathrm{K}^{+}$-ATPase in human erythrocyte membranes to be decreased in hyperthyroidism and to be associated with an increase in intracellular sodium concentration. ${ }^{27,29-33}$ The number of moles of ouabain that bind per red cell 
Table II Biochemical abnormalities of erythrocytes in hyperthyroidism

$\mathrm{Na}^{+}, \mathrm{K}^{+}$-ATPase activity decreased ${ }^{23-29}$

Sodium concentration increased ${ }^{27,29-33}$

$\mathrm{Ca}^{2+}$-ATPase activity increased ${ }^{39}$

Zinc concentration decreased ${ }^{27,32,40,42}$

B isoenzyme of carbonic anhydrase decreased $43-46$

Oxygen consumption and heat production increased 47,48

Increased activity of glucose-6-phosphate dehydrogenase and other enzymes that metabolise glucose 32,49

2,3-Diphosphoglycerate concentration increased ${ }^{56,58,59}$ Catalase activity increased ${ }^{62}$

Monoester lipase activity increased ${ }^{63}$

Percent haemoglobin $A_{2}$ increased ${ }^{04,65}$

Percent fetal haemoglobin increased ${ }^{65,66}$

is decreased $26,27,29,34$ which suggests that a decrease in the number of $\mathrm{Na}^{+}, \mathrm{K}^{+}$-ATPase sodium pumps per cell is responsible for the decrease in sodium efflux rather than a defect in performance of the pumps. A significant inverse relationship has been observed between the number of sodium pumps per erythrocyte and the plasma thyroxine and tri-iodothyronine levels. ${ }^{27,34}$ It has been suggested $25-28$ that the effects of thyroid hormone on the activity of the $\mathrm{Na}^{+}, \mathrm{K}^{+}$-ATPase are not specific but are a manifestation of a widespread effect on the metabolism or membrane environment of most surface proteins of the erythrocyte. However, extensive studies of the function and environment of erythrocyte surface proteins in hyperthyroidism have not been carried out and some of the existing data are controversial. For example, one group ${ }^{28}$ has reported a significant reduction in the number of insulin receptors per red blood cell in hyperthyroidism together with a significant increase in their average affinity, whereas another group ${ }^{35}$ has reported a marked decline in insulin binding affinity without change in insulin receptor number. The proposal ${ }^{36,37}$ that a generalized increase in $\mathrm{Na}^{+}, \mathrm{K}^{+}$-ATPase activity is responsible for a major proportion of the increased energy demand in hyperthyroidism appears not to include the erythrocyte. ${ }^{33}$ It may $b^{26}$ that the erythrocyte, being unable to carry out protein synthesis, cannot adequately replace certain proteins, such as components of the $\mathrm{Na}^{+}, \mathrm{K}^{+}$-ATPase sodium pump, whose rate of catabolism is increased in hyperthyroidism. ${ }^{38}$ On the other hand, $\mathrm{Ca}^{2+}$. ATPase activity of erythrocyte membranes was found to be increased in hyperthyroidism ${ }^{39}$ which suggests that no single explanation for the effect of thyroid hormone on components of the plasma membrane of the erythrocyte is likely.

There is general agreement that erythrocyte zincconcentration is reduced in hyperthyroidism $^{27.32,40.42}$ and that urinary zinc excretion is increased..$^{41,42}$ The concentration of the $B$ isoenzyme of carbonic anhydrase, which is by far the most abundant zinc metalloenzyme in the erythrocyte, is decreased in hyperthyroidism, whereas the concentration of the genetically distinct $\mathrm{C}$ isoenzyme is near normal. ${ }^{4-46}$ For example, Funakoshi and Deutsch ${ }^{46}$ found the mean levels of the B and $\mathrm{C}$ isoenzymes to be $37 \%$ and $80 \%$ of normal, respectively. The overall activity of carbonic anhydrase is decreased, but the activities of a number of other zinc metalloenzymes of the erythrocyte are unchanged in hyperthyroidism. ${ }^{40}$ It is likely that thyroid hormones specifically inhibit the synthesis of the B isoenzyme. This effect has not been associated with a change in erythrocyte function nor is it of sufficient magnitude to explain the negative zinc balance that occurs in thyrotoxicosis, ${ }^{41,42}$ a phenomenon which has been correlated with the overall catabolic state. ${ }^{41}$

Erythrocytes, which lack mitochondria, metabolise glucose via the Embden-Meyerhof glycolytic pathway and the hexose monophosphate shunt (also called the pentose phosphate shunt). ATP, the major energy source, is produced by the EmbdenMeyerhof pathway and the hexose monophosphate shunt yields NADPH which is used as a cofactor in a number of reactions. Oxygen consumption and heat production by erythrocytes from hyperthyroid patients are both increased ${ }^{4,48}$ and increased activities of a number of enzymes of intermediary metabolism in erythrocytes from hyperthyroid patients have been reported. ${ }^{32,49}$ Normally, most of the available glucose is utilized by the EmbdenMeyerhof pathway ${ }^{50}$ and recently it was reported ${ }^{51}$ that the metabolic activities of both pathways are proportionately increased in hyperthyroidism so that the Embden-Meyerhoff pathway continues to predominate. The mechanism by which thyroid hormones increase the metabolic activity of the erythrocyte is unknown but is of special interest since the erythrocyte lacks the two organelles which are usually postulated to be involved in the mechanism of action of thyroid hormones in other tissues, namely mitochondria and a nucleus.

In erythrocytes from hyperthyroid patients and from normal subjects treated with thyroid hormone the haemoglobin dissociation curve is shifted to the right indicating a decreased affinity for oxygen. ${ }^{52,53}$ A result of this shift is that oxygen is more readily delivered to peripheral tissues, perhaps to meet the increased metabolic demands of thyrotoxicosis. It is known ${ }^{54,55}$ that an increase in the concentration of organic phosphates within erythrocytes displaces the oxyhaemoglobin dissociation curve to the right. It has been reported that the concentration of 2,3diphosphoglycerate, the major source of organic phosphate in the erythrocyte, is increased after 
incubation in vitro of red cell preparations from normal subjects in medium containing thyroid hormones $^{56,57}$ and in the erythrocytes of some, ${ }^{56,58,59}$ but not all, ${ }^{60,61}$ patients with hyperthyroidism.

The activities of erythrocyte catalase ${ }^{62}$ and monoester lipase ${ }^{63}$ are increased in hyperthyroid patients but the mechanism and possible significance of these changes are unclear. The mean percent haemoglobin $\mathrm{A}_{2}$ level (3.21) in a group of untreated hyperthyroid subjects was significantly $(P<0.001)$ higher than in a group made euthyroid with antithyroid drugs (2.42). ${ }^{64}$ These results, which confirmed an earlier report, ${ }^{65}$ suggest that thyroid hormones can modulate the synthesis of globin chains. A slight elevation of the foetal haemoglobin percentage has also been reported. ${ }^{65,66}$

\section{Leucocytes}

\section{Absolute and relative numbers}

An association between neutropenia and Graves' disease has been recognized for at least 80 years. ${ }^{67,68}$ In relatively recent studies, the incidence of absolute neutropenia in hyperthyroid patients varied from less than $5 \%{ }^{16,69}$ to $18 \% .^{70} \mathrm{~A}$ significant relative neutropenia in thyrotoxic patients, originally described in $1908,{ }^{68}$ has also been confirmed in more recent years. ${ }^{69}$ Treatment of the neutropenic thyrotoxic patient with radioiodine or propylthiouracil usually results in a return of the neutrophil count to normal and neutropenia detected before treatment does not contraindicate the use of thioamide drugs. ${ }^{70}$ The aetiology of the neutropenia is unknown, but does not appear to involve depressed or ineffective myelopoiesis. ${ }^{11,12,70}$

Although there is general agreement that a relative lymphocytosis is often seen in hyperthyroid patients, ${ }^{16,68,69}$ there is less consensus regarding whether an absolute lymphocytosis is $\mathbf{1 6 , 6 8 , 7 1 , 7 2}$ or is not ${ }^{69,73}$ associated. There has also been disagreement regarding the relative and absolute numbers of $T$ lymphocytes and subsets. Table III gives the findings of several recent reports. The conflicting

Table III T and B lymphocytes in Graves' disease

\begin{tabular}{|c|c|}
\hline T lymphocytes (total number) & - normal $^{73,74}$ \\
\hline & - decreased ${ }^{72,75}$ \\
\hline Suppressor T lymphocytes (\%) & - normal $72,74.76$ \\
\hline & - decreased $^{73.75}$ \\
\hline Helper T lymphocytes (\%) & $\begin{array}{l}\text { - normal } \\
\text { - increased } \\
\text { in }\end{array}$ \\
\hline $\begin{array}{l}\text { Activated T lymphocytes (\%) } \\
\text { B lymphocytes (\%) }\end{array}$ & $\begin{array}{l}\text { - increased } \\
\text { - } \text { normal }^{73,76} \\
\text { - increased } \\
\text { inc }\end{array}$ \\
\hline
\end{tabular}

results are further complicated by the fact that the mean changes reported in a study often do not occur in all patients in that study. For example, one group $^{75}$ found a decrease in the proportion of suppressor $\mathrm{T}$ lymphocytes in only about $50 \%$ of patients. The lack of consistent findings in peripheral blood may be due to the fact that the pathogenetic immunological events in Graves' disease take place within the thyroid gland. ${ }^{77}$ Atypical lymphocytes may be seen in some patients with thyrotoxicosis. ${ }^{1,16}$ Monocyte and eosinophil counts are usually normal, ${ }^{16}$ although either may occasionally be modestly raised. ${ }^{1,72}$

\section{Biochemistry}

There have been surprisingly few investigations of possible changes in the metabolism of leucocytes in hyperthyroidism. In one study ${ }^{26}$ it was found that leucocyte $\mathrm{Na}^{+}, \mathrm{K}^{+}$-ATPase activity, $\left[{ }^{3} \mathrm{H}\right]$ ouabain binding capacity (an indicator of the number of sodium pumps) and total active rubidium influx (used to measure potassium flux) were all significantly increased in untreated hyperthyroidism. There was no change in leucocyte sodium concen? tration. These results contrasted with those founch. in erythrocytes which showed decreased $\mathrm{Na}^{+}, \mathrm{K}^{+} \frac{\mathrm{O}}{7}$ ATPase activity, decreased $\left[{ }^{3} \mathrm{H}\right]$ ouabain binding capacity and decreased active potassium flux rates.

A statistically significant decrease in phagocytic ability and an increase in nitroblue tetrazolium reduction by neutrophils from hyperthyroid patients compared to normal control subjects have been reported. ${ }^{78}$ Cytochemical observations suggested increased activity of leucocyte acid phosphatase and $\beta$-glucuronidase. Further studies of granulocyte function and metabolism in hyperthyroidism are needed.

Insulin binding to monocytes was found to be significantly decreased in a group of hyperthyroid patients as compared to a control group. ${ }^{79}$ The decrease was attributed to a decrease in receptor number rather than receptor affinity. It was suggested that peripheral insulin resistance might contribute to the glucose intolerance of thyrotoxicosis.

Several groups have studied the effects of thyrotoxicosis on the adrenergic receptor system of mononuclear leucocytes. It is generally agreed that there is an increase in the number of $\beta$ adrenergic receptors per cell. ${ }^{80-82}$ If, as some believe, hyperthyroidism is associated with an increased sensitivity to circulating catecholamines, it is possible that the mechanism involves a thyroid hormone-induced increase in adrenergic receptor density in a variety of responsive tissues. 


\section{Platelets and other coagulation factors}

Mean platelet volume was found to be increased in hyperthyroidism and the mean .platelet distribution width, which represents the coefficient of variation of the mean platelet width, was decreased. ${ }^{83}$ The lower mean value of the platelet distribution width observed in hyperthyroid patients suggested that platelet size was more uniform than in the euthyroid state. A larger, more uniform population of platelets in hyperthyroidism is consistent with the view that platelet lifespan is decreased but does not indicate the mechanism(s) involved. In fact, a shortened platelet survival time ${ }^{84,85}$ and an increase in megakaryocytes in bone marrow ${ }^{12}$ have been reported in hyperthyroid subjects even when platelet counts were normal.

There is a paucity of recent studies of platelet function and biochemistry in hyperthyroidism. Platelet adhesiveness, measured in vitro using glass beads, was found to be significantly increased in thyrotoxicosis and a decrease to normal was noted after treatment-induced euthyroidism. ${ }^{86}$ Platelet monoamine oxidase activity has been reported as normal ${ }^{87}$ and decreased ${ }^{88}$ in hyperthyroid subjects. Earlier studies also gave conflicting results perhaps due to different assay techniques used, different animal species studied and the wide variety of tissues investigated in addition to platelets. In another study, ${ }^{89} 8$ of 22 patients with Graves' disease and normal platelet counts were found to have elevated platelet-bound IgG and in these cases abnormal in vitro platelet aggregation measurements were observed, particularly with epinephrine.

The uncommon but well recognized association between hyperthyroidism and immune thrombocytopenia $^{90}$ continues to be the subject of case reports. ${ }^{91-94}$ In a substantial number of cases, a marked improvement or permanent reversal of the thrombocytopenia occurred after correction of the

\section{References}

1. Oppenheimer, J.H., Schwartz, H.L., Mariash, C.N., Kinlaw, W.B., Wong, N.C.W. \& Freake, H.C. Advances in our understanding of thyroid hormone action at the cellular level. Endocrine Rev 1987, 8: $288-308$.

2. Tudhope, G.R. Endocrine disorders. In: Israels, M.C.G. \& Delamore, I.W. (eds) Haematological Aspects of Systemic Disease. W.B. Saunders, London, 1976, pp. 162-200.

3. Herbert, V. The blood. In: Ingbar, S.H. \& Braverman, L.E. (eds) The Thyroid, 5th edition. J.B. Lippincott, Philadelphia, 1986, pp. 878-884.

4. Muldowney, F. P., Crooks, J. \& Wayne, E. J. The total red cell mass in thyrotoxicosis and myxoedema. Clin Sci 1957, 16: 309-314. hyperthyroidism and it is recommended, therefore, that glucocorticoid treatment of the immune thrombocytopenia should be persisted with until the patient has been euthyroid for about 4 weeks before considering additional immuno-suppressive therapy or splenectomy. The exact mechanism for the thrombocytopenia has not been established; however, platelets from such patients show elevated levels of bound immunoglobulins. ${ }^{89,94}$ It has been pointed out ${ }^{89}$ that platelet-bound IgG may not be specific for any platelet antigen, but rather may exist as part of an antigen-antibody complex bound to the Fc receptor of the cell.

Aside from possible functional abnormalities of platelets, ${ }^{89}$ the causes for the easy bruising and menorrhagia that are associated with hyperthyroidism have not been established. In fact, the mean levels of fibrinolytic activity and of plasminogen were reported to be significantly reduced in hyperthyroid patients ${ }^{95}$ and the mean levels of coagulation factor VIII and related properties significantly increased. ${ }^{96,97}$ Probably related to this effect on factor VIII is the significantly shortened partial thromboplastin time in hyperthyroid patients. Simone et al. ${ }^{96}$ observed no change from normal in clotting factors II, V, IX and X in hyperthyroid subjects; a significant depression of factor II levels has subsequently been reported by others, however. $^{98}$ When hyperthyroid patients receive warfarin, the decreases in factors II and VII are significantly greater than the effects observed in euthyroid subjects. ${ }^{98}$ This results in the hyperthyroid patient being more sensitive to the anticoagulant effects of warfarin. ${ }^{98-100}$ It is not clear how thyrotoxicosis causes these changes in coagulation function, but the altered response necessitates careful monitoring in such patients.

\section{Acknowledgement}

We are grateful to J. Ward for typing the manuscript.

5. Das, K.C., Mukherjee, M., Sarkar, T.K., Dash, R.J. \& Rastogi, G.K. Erythropoiesis and erythropoietin in hypo- and hyperthyroidism. J Clin Endocrinol Metab 1975, 40: 211-220.

6. Khojasteh, A. \& Perry, M.C. Thyrotoxic erythrocytosis. South Med J 1982, 75: 379-380.

7. Rodman, G.P. \& Jensen, W.N. A study of red blood cell survival in hypo- and hyperthyroidism. Clin Res 1957, 5: 8.

8. McClellan, J.E., Donegan, C., Thorup, O.A. \& Leavell, B.S. Survival time of the erythrocyte in myxedema and hyperthyroidism. J Lab Clin Med 1958, 51: 91-96. 
9. Gibson, J.G. II \& Harris, A.W. Clinical studies of the blood volume. V. Hyperthyroidism and myxedema. J Clin Invest 1939, 18: 59-65.

10. Peschle, C., Zanjani, E.D., Gidarl, A.S., McLaurin, W.D. \& Gordon, A.S. Mechanism of thyroxine action on erythropoiesis. Endocrinology 1971, 89: 609-612.

11. Golde, D.W., Bersh, N., Chopra, I.J. \& Cline, M.J. Thyroid hormones stimulate erythropoiesis in vitro. Br J Haematol 1977, 37: 173-177.

12. Popovic, W.J., Brown, J.E. \& Adamson, J.W. The influence of thyroid hormones on in vitro erythropoiesis. J Clin Invest 1977, 60: 907-913.

13. Dainiak, N., Sutter, D. \& Kreczko, S. LTriiodothyronine augments erythropoietic growth factor release from peripheral blood and bone marrow leukocytes. Blood 1986, 68: 1289-1297.

14. Bistrom, O. On the morphology of blood and bonemarrow in thyrotoxicosis. Acta Chir Scand 1946, (Suppl.) 114.

15. Axelrod, A.R. \& Berman, L. The bone marrow in hyperthyroidism and hypothyroidism. Blood 1951, 6: 436-453.

16. Donati, R.M., Warnecke, M.A. \& Gallagher, N.I. Ferrokinetics in hyperthyroidism. Ann Intern Med 1965, 63: 945-950.

17. Rivlin, R.S. \& Wagner, H.N. Anemia in hyperthyroidism. Ann Intern Med 1969, 70: 507-516.

18. Lahtinen, R. Sideroblasts and haemosiderin in thyrotoxicosis. Scand J Haematol 1980, 25: 237-243.

19. Nightingale, S., Vitek, P.J. \& Himsworth, R.L. The haematology of hyperthyroidism. $Q J$ Med 1978, 47: 35-47.

20. How, J., Davidson, R.J.L. \& Bewsher, P.D. Red cell changes in hyperthyroidism. Scand J Haematol 1979, 23: $323-328$

21. Reddy, J., Brownlie, B.E.W., Heaton, D.C., Hamer, J.W. \& Turner, J.G. The peripheral blood picture in thyrotoxicosis. $N Z$ Med J 1981, 93: 143-145.

22. Dintenfass, L., Forbes, C.D. \& McDougall, I.R. Blood viscosity in hyperthyroid and hypothyroid patients. Haemostasis 1974, 3: 348-352.

23. Cole, C.H. \& Waddell, R.W. Alteration in intracellular sodium concentration and ouabain-sensitive ATPase in erythrocytes from hyperthyroid patients. $J$ Clin Endocrinol Metab 1976, 42: 1056-1063.

24. Smith, E.K.M. \& Samuel, P.D. Abnormalities in the sodium pump of erythrocytes from patients with hyperthyroidism. Clin Sci 1970, 38: 49-61.

25. Michels, R.C., Ober, K.P. \& Hennessy, J.F. Cation transport in intact erythrocytes of hyperthyroid patients: role of the NaK-ATPase pump. Horm Metab Res 1981, 13: 635-638.

26. DeLuise, M. \& Flier, J.S. Status of the red cell Na, K-pump in hyper- and hypothyroidism. Metabolism 1983, 32: 25-30.

27. Rubython, E.J., Cumberbatch, M. \& Morgan, D.B. Changes in the number and activity of sodium pumps in erythrocytes from patients with hyperthyroidism. Clin Sci 1983, 64: 441-447.

28. Suzuki, K. \& Fujino, R. Alteration in activities of $\mathrm{Na}, \mathrm{K}$, ATPase, sugar transport and insulin receptors in erythrocytes from hyperthyroid patients. Metabolism 1986, 35: 371-377.
29. Khan, F.A. \& Baron, D.N. Ion influx and $\mathrm{Na}^{+}, \mathrm{K}^{+}$ ATPase activity of erythrocytes and leucocytes in thyroid disease. Clin Sci 1987; 72: 171-179.

30. Sutterlin, U., Gless, K-H., Schaz, K., Hufner, M., Schutz, V. \& Hunstein, W. Peripheral effects of thyroid hormones: alteration of intracellular $\mathrm{Na}$ concentration, ouabain-sensitive $\mathrm{Na}$-transport, and $\mathrm{Na}-\mathrm{Li}$ countertransport in human red blood cells. Klin Wochenschr 1984, 62: 598-601.

31. Boekelman, W.A. Sodium content of erythrocytes in hyperthyroidism. Nature 1958, 181: 1136.

32. Swaminathan, R., Chapman, C., Segall, N.H. \& Morgan, D.B. Red-blood-cell composition in thyroid disease. Lancet 1976, ii: 1382-1385.

33. Monti, M., Hedner, P., Ikomi-Kumm, J. \& Valdemarsson, S. Erythrocyte thermogenesis in hyperthyroid patients: microcalorimetric investigation of sodium/potassium pump and cell metabolism. Metabolism 1987, 36: 155-159.

34. Suzuki, K., Kadowaki, T., Sekimizu, M. \& Shishiba, Y. Erythrocyte ouabain binding capacity as a possible cellular index of hyperthyroid status. Endocrinol Jpn 1983; 30: 609-614.

35. Laville, M., Riou, J.P., Bougneres, P.F. et al. Glucose metabolism in experimental hyperthyroidism: intact in vivo sensitivity to insulin with abnormal binding and increased glucose turnover. $J$ Clin Endocrinol Metab 1984, 58: 960-965.

36. Edelman, I.S. Thyroid thermogenesis. $N$ Engl J Med 1974, 290: 1303-1308.

37. Smith, T.J. \& Edelman, I.S. The role of sodium transport in thyroid thermogenesis. Fed Proc 1979, 38: $2150-2153$.

38. Flaim, K.E., Li, J.B. \& Jefferson, L.S. Effects of thyroxine on protein turnover in rat skeletal muscle. Am J Physiol 1978, 235: E231-E237.

39. Dube, M.P., Davis, F.B., Davis, P.J. Schoenl, M. \& Blas, S.D. Effects of hyperthyroidism and hypothyroidism on human red blood cell $\mathrm{Ca}^{2+}$-ATPase activity. J Clin Endocrinol Metab 1986, 62: 253-257.

40. Pangaro, J.A., Weinstein, M., Devetak, M.C. \& Soto, R.J. Red cell zinc and red cell zinc metalloenzymes in hyperthyroidism. Acta Endocrinol 1974, 76: 645-650.

41. Bremner, W.F. \& Fell, G.S. Zinc metabolism and thyroid status. Postgrad Med J 1977, 53: 143-145.

42. Nishi, Y., Kawate, R. \& Usui, T. Zinc metabolism in thyroid disease. Postgrad Med J 1980, 56: 833-837.

43. Weatherall, D.J. \& McIntyre, P.A. Developmental and acquired variations in erythrocyte carbonic anhydrase isozymes. $\mathrm{Br}$ J Haem 1967, 13: 106-114.

44. Magid, E. Determination of erythrocyte carbonic anhydrase B \& C: an aid in the diagnosis of thyroid disorders? Scand J Clin Lab Invest 1970, 26: 257-262.

45. Funakoshi, S. \& Deutsch, H.F. Human carbonic anhydrase. V. Levels in erythrocytes in various states. J Lab Clin Med 1971, 77: 39-45.

46. Anker, N. \& Mondrup, M. Carbonic anhydrase isoenzyme B in erythrocytes of subjects with thyroid disorders. Clin Chim Acta 1974, 54: 277-282.

47. Angelone, L., Watkins, D.H. \& Angerer, C.A. Oxygen consumption of erythrocytes from patients with various thyroid conditions related to their respective 
serum protein-bound iodine concentrations. Blood 1954, 9: 953-958.

48. Monti, M. \& Wadso, I. Microcalorimetric measurements of heat production in human erythrocytes. II. Hyperthyroid patients before, during and after treatment. Acta Med Scand 1976, 200: 301-308.

49. Goebel, K.M., Goebel, F.D., Neitzert, A., Hausmann, L. \& Schneider, J. Adaptation of red cell enzymes and intermediates in metabolic disorders. Enzyme 1975, 19: 201-211.

50. Murphy, J.R. Erythrocyte metabolism. II. Glucose metabolism and pathways. J Lab Clin Med 1960, 55: 286-302.

51. Monti, M., Hedner, P., Ikomi-Kumm, J. \& Valdemarsson, S. Erythrocyte metabolism in hyperthyroidism: a microcalorimetric study on changes in the Embden-Meyerhof and the hexose monophosphate pathways. Acta Endocrinol 1987, 115: 87-90.

52. Bansi, H.W. \& Groscurth, G. Veranderungen der Sauerstoffbindungskurven des Blutes bei Stoffwechsel- und Blutkrankheiten (Anamie und Polycythamie). Z Klin Med 1930, 113: 560-575.

53. Gahlenbeck, H. \& Bartels, H. Veranderung der Sauerstoffbindungskurven des Blutes bei Hyperthyreosen und nach Gabe von Trijodthyronin bei Gesunden und bei Ratten. Klin Wochenschr 1968, 46: 547-548.

54. Benesch, R. \& Benesch, R.E. The effect of organic phosphates from the human erythrocyte on the allosteric properties of hemoglobin. Biochem Biophys Res Commun 1967, 26: 162-167.

55. Chanutin, A. \& Curnish, R.R. Effect of organic and inorganic phosphates on the oxygen equilibrium of human erythrocytes. Arch Biochem Biophys 1967, 121: 96-102.

56. Miller, L.D., Sugarman, H.J., Miller, W.W. et al. Increased peripheral oxygen delivery in thyrotoxicosis: role of red cell 2,3-diphosphoglycerate. Ann Surg 1970, 172: 1051-1058.

57. Snyder, L.M. \& Reddy, W.J. Thyroid hormone control of erythrocyte 2,3-diphosphoglyceric acid concentrations. Science 1970, 169: 879-880.

58. Monti, M. Red cell 2,3-diphosphoglycerate in patients with hyperthyroidism before and after treatment. Acta Med Scand 1974, 196: 263-266.

59. Alvarez-Sala, J.L., Urban, M.A., Sicilia, J.J., Diaz Fdez, A.J., Fdez Mendieta, F. \& Espinos, D. Redcell 2,3-diphosphoglycerate in patients with hyperthyroidism. Acta Endocrinol 1980, 93: 424-429.

60. Viherkoski, M. \& Lamberg, B-A. The glucose-6phosphate dehydrogenase activity (G-6-PD) of the red blood cells in hyperthyroidism and hypothyroidism. Scand J Clin Lab Invest 1970, 25: 137-143.

61. Zaroulis, C.G., Kourides, I.A. \& Valeri, C.R. Red cell 2,3-diphosphoglycerate and oxygen affinity of hemoglobin in patients with thyroid disorders. Blood 1978, 52: 181-185.

62. Kurasaki, M., Saito, T., Kaji, H., Kojima, Y. \& Saito, K. Increased erythrocyte catalase activity in patients with hyperthyroidism. Horm Metab Res 1986, 18: 56-59.

63. Cohen, J., Somma-Delpero, C., Verine, A., Codaccioni, J.L. \& Boyer, J. Increased monoester lipase activity in red blood cells during hyperthyroidism. $J$ Endocrinol 1986, 108: 357-359.

64. Kuhn, J-M., Rieu, M., Rochette, J. et al. Influence of thyroid status on hemoglobin $\mathrm{A}_{2}$ expression. $J$ Clin Endocrinol Metab 1983, 57: 344-348.

65. Kendall, A.G. \& Bastomsky, C.H. Hemoglobin $\mathrm{A}_{2}$ in hyperthyroidism. Hemoglobin 1981, 5: 571-577.

66. Fuhr, J.E. \& Dunn, C.D.R. Control of hemoglobin synthesis in fetal erythroid cells by L-thyroxine. Am J Hematol 1978, 5: 163-168.

67. Caro-Posen, L. Ein Fall von malignem Morbus Basedowii kombiniert mit den Symptomen der Pseudoleukamie. Berl Klin Wochenschr 1907, 54: 519-520.

68. Kocher, T. Blutintersuchungen bei Morbus Basedowii mit Beitrage zur Fruhdiagnose und Theorie der Krankheit. Arch Klin Chirurg 1908, 87: 131-157.

69. Irvine, W.J., Wu, F.C.W., Urbaniak, S.J. \& Toolis, F. Peripheral blood leucocytes in thyrotoxicosis (Graves' disease) as studied by conventional light microscopy. Clin Exp Immunol 1977, 27: 216-221.

70. Eakin, D.L., Peake, R.L. \& Weiss, G.B. Effect of therapy on the neutropenia of hyperthyroidism. South Med J 1983, 76: 335-340.

71. Mori, H., Amino, N. Iwatani, Y. et al. Increase of peripheral B lymphocytes in Graves' disease. Clin Exp Immunol 1980, 42: 33-40.

72. Iwatani, Y., Amino, N., Mori, H. et al. T lymphocyte subsets in autoimmune thyroid diseases and subacute thyroiditis detected with monoclonal antibodies. J Clin Endocrinol Metab 1983, 56: 251-254.

73. Chan, J.Y.C. \& Walfish, P.G. Activated $\left(\mathrm{Ia}^{+}\right)$ T-lymphocytes and their subsets in autoimmune thyroid diseases: analysis by dual laser flow microfluorocytometry. J Clin Endocrinol Metab 1986, 62: 403-409.

74. Van Ouwerkerk, B.M., Krenning, E.P., Doctor, R., et al. Cellular and humoral immunity in patients with hyperthyroid Graves' disease before, during and after antithyroid drug treatment. Clin Endocrinol 1987, 26: 385-394.

75. Madec, A.M., Allannic, H., Genetet, N. et al. T lymphocyte subsets at various stages of hyperthyroid Graves' disease: effect of carbimazole treatment and relationship with thyroid-stimulating antibody levels or HLA status. J Clin Endocrinol Metab 1986, 62: $117-121$.

76. Buse, J.B. \& Eisenbarth, G.S. Autoimmune endocrine disease. Vitam Horm 1985, 42: 253-314.

77. Volpe, R. Immunoregulation in autoimmune thyroid disease. $N$ Engl J Med 1987, 316: 44-46.

78. Hrycek, A. \& Kalina, Z. Changes in the metabolism and functions of peripheral blood neutrophils in patients with thyroid diseases. Endokrynol Pol 1984, 35: $45-50$.

79. Schernthaner, G., Prager, R., Weissel, M. \& Hofer, $\mathrm{R}$. Decreased insulin receptor binding in hyperthyroidism. Klin Wochenschr 1984, 62: 1074-1080.

80. Ginsberg, A.M., Clutter, W.E., Shah, S.D. \& Cryer, P.E. Triiodothyronine-induced thyrotoxicosis increases mononuclear leukocyte $\beta$-adrenergic receptor density in man. $J$ Clin Invest 1981, 67: 1785-1791.

81. Andersson, R.G.G., Nilsson, O.R. \& Kuo, J.F. 
$\boldsymbol{\beta}$-Adrenoreceptor-adenoside, $\quad 3^{\prime}, 5^{\prime}$-monophosphate system in human leucocytes before and after treatment for hyperthyroidism. J Clin Endocrinol Metab 1983, 56: 42-45.

82. Ratge, D., Hansel-Bessey, S. \& Wisser, H. Altered plasma catecholamines and number of $\alpha$ - and $\beta$ adrenergic receptors in platelets and leucocytes in hyperthyroid patients normalized under antithyroid treatment. Acta Endocrinol 1985, 110: 75-82.

83. Ford, H.C., Toomath, R.J., Carter, J.M. et al. Mean platelet volume is increased in hyperthyroidism. $\mathrm{Am}$ J Hematol 1988, 27: 190-193.

84. Lamberg, B-A., Kivikangas, V., Pelkonen, R. \& Vuopio, P. Thrombocytopenia and decreased lifespan of thrombocytes in hyperthyroidism. Ann Clin Res 1971, 3: 98-102.

85. Kurata, Y., Nishioeda, Y., Tsubakio, T. \& Kitani, T. Thrombocytopenia in Graves' disease: effect of $T_{3}$ on platelet kinetics. Acta Haematol 1980, 63: 185-190.

86. Hellem, A.J., Segaard, E. \& Solem, J.H. The adhesiveness of human blood platelets and thyroid function. Acta Med Scand 1975, 197: 15-17.

87. Feldman, J.M. \& Roche, J. Effect of hyper- and hypothyroidism on platelet monoamine oxidase activity and serotonin metabolism. Metabolism 1977, 26: 657-664.

88. Singh, H.C., Sarkar, F.H., Singh, R.H. \& Udupa, K.N. Blood platelet monoamine oxidase and acetylcholinesterase in thyrotoxicosis. Indian $\mathrm{J}$ Med Res 1980, 71: 384-386.

89. Hymes, K., Blum, M., Lackner, H. \& Karpatkin, S. Easy bruising, thrombocytopenia, and elevated platelet immunoglobulin G in Graves' disease and Hashimoto's thyroiditis. Ann Intern Med 1981, 94: 27-30.
90. Jackson, A.S. Acute hemorrhagic purpura associated with exophthalmic goiter. JAMA 1931, 96: 38-39.

91. Herman, J., Resnitzky, P. \& Fink, A. Association between thyrotoxicosis and thrombocytopenia. Israel J Med Sci 1978, 14: 469-475.

92. Adrouny, A., Sandler, R.M. \& Carmel, R. Variable presentation of thrombocytopenia in Graves' disease. Arch Intern Med 1982, 142: 1460-1464.

93. Liechty, R.D. The thyrotoxicosis/thrombocytopenia connection. Surgery 1983, 94: 966-968.

94. Jacobs, P., Majoos, F. \& Perrotta, A. Hyperthyroidism and immune thrombocytopenia. Postgrad Med J 1984, 60: 657-661.

95. Rennie, J.A.N., Bewsher, P.D., Murchison, L.E. \& Ogston, D. Coagulation and fibrinolysis in thyroid disease. Acta Haematol 1978, 59: 171-177.

96. Simone, J.V., Abildgaard, C.F. \& Schulman, I. Blood coagulation in thyroid dysfunction. $N$ Engl $J$ Med 1965, 273: 1057-1061.

97. Rogers, J.S., Shane, S.R. \& Jencks, F.S. Factor VIII activity and thyroid function. Ann Intern Med 1982, 97: 713-716.

98. Kellett, H.A., Sawers, J.S.A., Boulton, F.E. et al. Problems of anticoagulation with warfarin in hyperthyroidism. $Q J$ Med 1986, 58: 43-51.

99. Self, T., Weisburst, M., Wooten, E., Straughn, A. \& Oliver, J. Warfarin-induced hypoprothrombinemia potentiation by hyperthyroidism. JAMA 1975, 231: 1165-1166.

100. Shenfield, G.M. Influence of thyroid dysfunction on drug pharmacokinetics. Clin Pharmacokinet 1981, 6: 275-297. 